\title{
The Ethics of Implementing First-trimester Risk Assessment
}

\author{
${ }^{1}$ Frank A Chervenak, ${ }^{2}$ Laurence B McCullough \\ ${ }^{1}$ Weill Medical College of Cornell University, The New York Presbyterian Hospital, New York, NY 10021 \\ ${ }^{2}$ Center for Medical Ethics and Health Policy, Baylor College of Medicine, Houston TX 77030
}

Correspondence: Frank A Chervenak

The New York-Presbyterian Hospital, Weill Medical College of Cornell University

525 East 68th Street, M-7, New York, NY 10021

Phone: 212-746-3045, Fax: 212-746-8960

\begin{abstract}
First trimester risk assessment has become a reliable screening tool for trisomy 21, replacing age-based risk assessment. On the basis of the ethical concept of the physician as fiduciary, the professional virtues of integrity and self-sacrifice, and the ethical principles of respect for autonomy, beneficence, and justice, we argue that the obstetrician has an ethical obligation to routinely offer pregnant women first trimester risk assessment in high quality centers. We then argue that both obstetricians and specialists in risk assessment have a strict ethical obligation to identify, responsibly manage, and disclose both economic and non-economic conflicts of interests, especially when they are hidden Ethics is an essential dimension of implementation of first trimester risk assessment for trisomy 21.
\end{abstract}

Key words: Ethics; physician as fiduciary; professional virtues; ethical principles; first trimester risk assessment; conflict of interest.

\section{INTRODUCTION}

For more than two decades we explored the essential role that ethics plays in obstetrics and gynecology. ${ }^{1}$ Obstetric ultrasound examination is a quintessential example of such a clinical topic. When routine second-trimester ultrasound examination was controversial in the 1980s, we defended the clinical ethical concept of prenatal informed consent for sonogram (PICS): all pregnant women should routinely be offered such evaluation, provided that it meets accepted standards of quality. ${ }^{2,3}$ When first-trimester ultrasound examination became controversial earlier in this decade, we defended the position that the concept of PICS should be expanded to first-trimester ultrasound evaluation as well, again with the provision of adherence to accepted standards of quality. ${ }^{4,5}$ The science has now evolved to the point that high quality first-trimester risk assessment that combines ultrasound evaluation with biochemistry is no longer experimental, because it has been shown to be a reliable screening tool. This conclusion is based not only on the longstanding contributions of the Fetal Medicine Foundation, ${ }^{6,7}$ but also on recent contributions from American centers, ${ }^{8,9}$ and on the basis of the recent consensus conference of the practice bulletin of the American College of Obstetricians and Gynecologists. ${ }^{10}$ Drawing on our previous work, ${ }^{11}$ the purpose of this paper is to demonstrate how ethical analysis and argument constitute an essential component of implementing firsttrimester risk assessment for trisomy 21.

\section{THE TOOLS OF ETHICS}

Ethics has been understood in global intellectual traditions since ancient times to be the disciplined study of morality. Morality concerns actual beliefs about how we should act and what sort of people we should want to become, our actual behavior, and the policies and practices of organizations, societies, and governments. ${ }^{1}$ Medical ethics is the disciplined study of medical morality and is also global. ${ }^{1}$ For most of its history, medical ethics involved appeals to a variety of sources, both theological and non-theological. Starting in the European Renaissance in a series of texts entitled Medicus Politicus (The Politic Doctor) that began to appear in the seventeenth century, medical ethics began to move away from theological sources and to become self-consciously secular. ${ }^{12,13}$ Physician-ethicists such as Roderigo de Castro in Spain and Friedrich Hoffmann in Germany understood themselves to be arguing for what medical morality ought to be in ways that did not require appeal to religious sources of morality. Their goal was to articulate a medical ethics for physicians in the emerging pluralistic societies of Renaissance Europe. This trend toward secular medical ethics accelerated and consolidated itself during the Scottish and English enlightenments of the late eighteenth century, especially in the writings of the physician-ethicists as John Gregory from Scotland and Thomas Percival from England. Their work has influenced the entire subsequent history of medical ethics in Europe and the Americas. ${ }^{14}$ 
Gregory and Percival should be given credit for creating the ethical concept of the physician as fiduciary of the patient, which became the basis for medicine becoming a profession over the past two centuries. This concept, which means that the physician is worthy of the trust of patients and society, has three components. First, the physician should be scientifically and clinically competent, by practicing medicine and conducting research to standards of intellectual excellence. Under the strong and self-conscious influence of Francis Bacon's philosophy of medicine, Gregory and Percival called for clinical competence to be defined in terms of adherence to the best evidence available. Second, the physician should make his or her primary commitment and motivation the protection and promotion of the patient's health-related interests and keep his or her selfinterest, especially economic self-interest, systematically secondary. Third, physicians should commit to medicine as a public trust for the benefit of future patients and should reject the concept of medicine as a private guild or association created primarily to protect the interests and advantages of its members. ${ }^{14}$

Two professional virtues are especially relevant for putting the ethical concept of the physician as fiduciary into clinical practice. ${ }^{1}$ The professional virtue of integrity is the commitment to practice, teach, and conduct research to standards of intellectual and moral excellence. The professional virtue of self-sacrifice requires physicians to ethically justify any claim that self-interest should take priority over obligations to patients. The physician bears the burden of proof in this argument and the burden is steep.

Ethical principles also put the ethical concept of the physician as fiduciary into practice. ${ }^{1}$ The oldest ethical principle is beneficence: the obligation of a physician to undertake clinical management that is reliably expected to result in a greater balance of clinical goods over clinical harms for the patient. The second principle, with origins in seventeenth-century surgery ${ }^{15}$ and nineteenth-century gynecology, ${ }^{16}$ is respect for autonomy. This principle requires physicians to acknowledge the integrity of each patient's values and beliefs, provide her with information that she needs to make decisions about her clinical care, and to implement her decisions unless there is some ethically compelling reason not to do so. The third ethical principle, justice, applies to populations of patients. This principle requires physicians and society to be fair in the allocation of resources and in the creation of opportunity to have access to clinical services.

None of these ethical principles should be regarded as an absolute, i.e. always having priority over the others. Instead, each principle is prima facie: it should be followed unless there is a well-made argument in favor of overriding that principle. ${ }^{1,17}$

The tools of ethics are ethical analysis and argument. ${ }^{16}$ Ethical analysis requires us to be clear in how we articulate basic ethical concepts, such as being a fiduciary, and ethical virtues and principles. Failure to be clear about basic concepts disables ethical reasoning. Ethical argument requires us to give reasons in support of judgments and recommendations using ethical concepts, virtues, and principles.

\section{AUTONOMY-BASED CONSIDERATIONS}

The emergence of high quality, reliable first-trimester risk assessment for trisomy 21 has crucial importance for the implementation of the ethical principle of respect for autonomy in the management of pregnancy. First, it is well recognized in the ethics of informed consent that, as part of fiduciary responsibility, physicians have an obligation to provide information to patients about all of the medically reasonable alternatives for managing the patient's condition or problem. ${ }^{19}$ First-trimester risk assessment has been shown to be a reliable screening tool, ${ }^{6-8}$ making it a form of medically reasonable management that must be presented as an option to all pregnant women as soon as they are diagnosed to be pregnant in the first trimester. ${ }^{20}$ Given the quantum increase in precision of risk assessment over the traditional reliance on age 35 at delivery, the latter can no longer be regarded as a medically reasonable alternative for the purposes of risk assessment for trisomy $21 .^{21-23}$ Second, providing the results of such risk assessment enhances the autonomy of pregnant women because doing so provides women with the information that they need to make an informed decision about whether to accept the benefits and risks of subsequent invasive diagnostic testing and about whether to continue their pregnancy or not. Third, there are empirical data that validate the ethical implications of respect for autonomy. Recent data demonstrate that pregnant women in Australia, Europe, and the United States want this information. ${ }^{24-27}$ Recent data also document that pregnant women can use sophisticated risk assessment information to make decisions about invasive testing, with the preference for invasive testing dropping dramatically as the risk estimate of trisomy 21 decreases. This indicates that pregnant women can use this information in an intellectually disciplined way. ${ }^{21}$

The option of risk assessment should be presented nondirectively. That is, the physician should offer risk assessment in a high quality center as an option to consider and explain that reliance on age alone is no longer regarded as medically reasonable. The options of forgoing risk assessment altogether and of proceeding directly to invasive testing should also be presented. Non-directive counseling, when followed assiduously, protects the autonomy of pregnant women to decide for themselves which of the three alternatives is acceptable to them. Obviously, results of first-trimester risk assessment should be presented non-directively. ${ }^{20}$

There is currently scientific debate about whether firsttrimester risk assessment should be used in conjunction with further evaluations such as ultrasound evaluation and 
biochemistry, as the basis for a more precise risk assessment. There is, however, no remaining controversy that first-trimester risk assessment in high quality centers is a reliable screening tool. It is therefore incompatible with the ethical principle of respect for autonomy and the ethics and law of the informed consent process to withhold the results of first-trimester risk assessment. $^{20}$

\section{BENEFICENCE-BASED CONSIDERATIONS}

Before viability, respect for autonomy is justifiably the dominant ethical consideration. Nonetheless, there are significant beneficence-based considerations. The main clinical benefit of first-trimester risk assessment is that the better definition of risk for women, especially those over 35, results in women choosing invasive testing less frequently when their estimate risk is less than $1 / 300 .^{27,28}$ This means that there are fewer fetal losses than occur using the current, outmoded age-related risk assessment. There may also be psychosocial benefits from early reassurance when the risk estimate is very low-an hypothesis that should be empirically studied.

\section{JUSTICE-BASED CONSIDERATIONS}

Decisions about the diagnosis and management of fetal anomalies constitute an essential exercise of patient autonomy. ${ }^{29}$ These decisions are therefore wholly unlike the autonomy-based decisions regarding cosmetic medicine and surgery. Decisions about the latter involve, at best, convenient exercises of autonomy that in no way involve such momentous decisions as whether to have risk assessment, to have invasive diagnostic testing, and to remain pregnant. In other words, not all autonomy-based indications for clinical management are alike.

The ethical principle of justice, in its most general formulation, requires that all like cases be treated alike and unlike cases treated unlike.,17 The cost of cosmetic medicine and surgery should be borne by the patient, not because having such procedures is based on autonomy, but because this decision is based on matters of convenience or personal preference and desire that can and do vary enormously from patient to patient. The cost of first trimester risk assessment should not be borne solely by the patient, because an essential exercise of autonomy is at stake. This is directly analogous to end-of-life care, for the cost of which patients are not held solely responsible. Physicians should therefore advocate for payment for quality first-trimester risk assessment by third-party payers in a reasonable arrangement for deductibles and co-payments.

\section{VIRTUE-BASED CONSIDERATIONS}

Professional integrity requires that first-trimester risk assessment consistently meets rigorous standards of quality. Current evidence indicates that ultrasound examination of nuchal thickness by physicians who have not been certified to meet accepted standards involves unacceptable variation that undermines the exercise of patient autonomy. ${ }^{9}$ This is directly analogous to the experience with second-trimester ultrasound examination. ${ }^{30}$

The professional virtues of integrity and self-sacrifice require physicians to identify and manage conflicts of interest responsibly, i.e. conflicts between fiduciary responsibility for patients and self-interest. There can be economic and noneconomic conflicts of interest, and both types should be regarded as ethically challenging.

It is crucial to distinguish conflicts of interest that, from a patient's perspective, are obvious from those that are hidden. Physicians who provide first-trimester risk assessment or invasive genetic diagnosis, as well as laboratories performing biochemical tests, have an obvious economic conflict of interest. Patients can be reliably assumed to know that such economic conflicts of interest exist. ${ }^{31}$

Patients should not be assumed to know about the existence and magnitude of hidden conflicts of interest neither should physicians in all cases. Hidden conflicts of interest occur, for example, for patent holders of first trimester risk assessment processes. Physicians who conduct research in this area can have non-economic conflicts of interest related to such matters as prestige and standing in the field. Physicians in leadership positions, e.g. board members of certifying groups or laboratories, also have economic as well as non-economic conflicts of interest.

Conflicts of interest are ethically significant in medicine because they pose a direct threat to all three components of fiduciary responsibility. Conflicts of interest can bias clinical judgment and decision making, threatening to distort of undermine the physician's scientific and clinical competence. Depending on their nature and the ability of the physician to withstand them, conflicts of interest can invite the physician to place self-interest first without ethical justification. Groups of physicians with a vested interest in providing first-trimester risk assessment, regulating it, or conducting research about it could band together and place their group or guild interests ahead of patients' interests without ethical justification. In short, conflicts of interest should be viewed as serious threats to professional integrity and self-sacrifice. Conflicts of interest therefore require careful assessment and management.

Four criteria have been proposed for the assessment of conflicts of interest, whether obvious or hidden. The first concerns how intense the conflict of interest is, i.e. what percent of the physician's earnings is at stake. The second concerns how immediate the conflict is, i.e. whether a physician's first consideration is the impact of clinical decisions on his or her economic or other self-interests, rather than on the pregnant woman's well being. The third concerns how systematic the conflict is, i.e. whether a physician's dominant and repeated 
consideration is about the impact of clinical decisions on his or her self-interests. The fourth concerns whether the physician is dealing in isolation with conflicts of interest or in the context of an organizational culture of accountability designed to protect professional and organizational integrity. ${ }^{32}$

The higher on each of these four domains the conflict of interest should be judged to be, the more unstable, and therefore unmanageable, it should be judged to be. The burden of proof is on the physician that the domains should be judged to be in the low, and therefore manageable, range. This means, as a practical matter, that uncertainty of assessment should be resolved in the direction of assuming that the conflict is high unless proven low. The purpose of this assumption is to prevent self-deception, which can lead rapidly to inappropriate protection of self-interest in violation of the professional virtue of self-sacrifice. The problem of self deception becomes especially challenging in the case of hidden conflicts of interest, which therefore require even more rigorous assessment.

Non-directive counseling plays a major role in the responsible management of conflicts of interest in first-trimester risk assessment. Its reliability is directly linked to the quality of the ultrasound evaluation and most obstetricians in private practice do not meet accepted international standards for quality. As a matter of professional integrity, they must therefore refer to high quality centers and should not allow potential lost revenues to influence their routinely offering this option. As a matter of professional integrity, referral centers should routinely return patients to the referring physician. Subsequent to counseling, the pregnant woman must be offered all options for invasive testing, including early testing that her obstetrician may not perform. Obstetricians and referral maternal-fetal medicine subspecialists will maintain their professional integrity in the management of their conflicts of interest by adhering strictly to the requirements of non-directive counseling at every stage of the informed consent process for and after first-trimester risk assessment.

Physicians in policy-making positions in professional societies, certifying groups, healthcare organizations, and government should be required, at a minimum, to disclose all hidden conflicts of interest. This disclosure of the presence, but not the magnitude of a hidden conflict of interest, however, provides no assurance that the requirements of professional integrity are being met. Simple disclosure can involve strategic ambiguity that invites unwarranted confidence that the hidden conflict of interest is both manageable and in fact well managed. Professional societies, certifying groups, healthcare organizations, and governments therefore should articulate and defend criteria they will use in a transparent process to judge hidden conflicts of interest to be ethically unacceptable, and therefore require the physician with them either to eliminate the conflict of interest or resign his or her position. The same standards should be developed and applied in continuing medical education in first-trimester risk assessment.

\section{CONCLUSION}

Ethics is an essential component of implementing first-trimester risk assessment for trisomy 21, with important implications for individual physicians, healthcare organizations, professional societies, and government. Professional integrity requires that the ethical dimensions of first-trimester risk assessment for trisomy 21 be explicitly acknowledged and addressed.

\section{REFERENCES}

1. McCullough LB, Chervenak FA. Ethics in Obstetrics and Gynecology. New York, Oxford University Press, 1994.

2. Chervenak FA, McCullough LB, Chervenak JL. Prenatal informed consent for sonogram: an indication for obstetric ultrasonography. Am J Obstet Gynecol 1989;161:857-60.

3. Chervenak FA, McCullough LB. Ethics and routine ultrasonography in pregnancy. Am J Obstet Gynecol 1990;163:257-58.

4. Chasen ST, Skupski DW, McCullough LB, Chervenak FA. Prenatal informed consent for sonogram: the time for firsttrimester nuchal translucency has come. J Ultrasound Med 2001;20:1147-52.

5. Chasen ST, Skupski DW, Chervenak FA, McCullough LB. Firsttrimester nuchal translucency screening: reply. J Ultrasound Med 2002;21:481,483-87.

6. Nicolaides KH. Nuchal translucency and other first-trimester sonographic markers of chromosomal abnormalities. Am J Obstet Gynecol 2004;191:45-67.

7. Avgidou K, Papageorghiou A, Bindra R, Spencer K, Nicolaides $\mathrm{KH}$. Prospective screening for trisomy 21 in 30,564 pregnancies in a one stop clinic at 11-13 weeks. Am J Obstet Gynecol 2005;192:1761-67.

8. Wapner R, Thom E, Simpson JL et al. First-trimester screening for trisomies 21 and 18. N Engl J Med 2003;349:1405-13.

9. Malone FD, Wald NJ, Canick JA, Ball RH, Nyberg DA, Comstock $\mathrm{CH}$, et al. First- and second-trimester evaluation of risk (FASTER) trial: Principal results of the NICHD multicenter Down syndrome screening study. Am J Obstet Gynecol 2003;S56 (abstract).

10. American College of Obstetrics and Gynecology. Committee on Practice Bulletins. Screening for fetal chromosomal abnormalities. Obstet Gynecol 2007;109:217-27.

11. Chervenak FA, McCullough LB. Implementation of firsttrimester risk assessment for trisomy 21: ethical considerations. Am J Obstet Gynecol 2005;192: 1777-81.

12. Geyer-Kordesch J. Natural law and medical ethics in the eighteenth century. In Baker R, Porter D, Porter R (Eds): The Codification of Medical Morality: Historical and Philosophical Studies of the Formalization of Western Medical Morality in the Eighteenth and Nineteenth Centuries. Volume One: Medical Ethics and Etiquette in the Eighteenth Century. Dordrecht, The Netherlands: Kluwer Academic Publishers, 1993;123-39. 
13. Schleiner W. Medical Ethics in the Renaissance. Washington, DC: Georgetown University Press, 1995.

14. McCullough LB. John Gregory and the Invention of Professional Medical Ethics and the Profession of Medicine. Dordrecht, The Netherlands, Kluwer Academic Publishers, 1998.

15. Wear A. Medical ethics in early modern England in Wear A, Geyer-Kordesch J, French P (Eds): Doctors and Ethics: The Earlier Historical Setting of Professional Ethics. Amsterdam and Atlanta, Rodopi, 1993;98-130.

16. Powderly KE. Patient consent and negotiation in the Brooklyn gynecological practice of Alexander JC Skene: 1863-1900. J Med Philos 2000;25:12-27.

17. Beauchamp TL, Childress JF. Principles of biomedical ethics. (5th edn). New York: Oxford University Press 2001.

18. McCullough LB, Coverdale JM, Chervenak FA. Argumentbased medical ethics: a formal tool for critically appraising the normative medical ethics literature. Am J Obstet Gynecol 2004;30:659-64.

19. Faden RR, Beauchamp TL. A History and Theory of Informed Consent. New York: Oxford University Press, 1986.

20. Chervenak FA, McCullough LB, Chasen ST. Clinical implications of the ethics of informed consent for first-trimester risk assessment for trisomy 21. Seminars in Perinatol 2005;29:277-79.

21. Nicolaides KH, Chervenak FA, McCullough LB, Avgidou K, Papageorghiou A. Evidence-based obstetrical ethics and informed decision-making by pregnant women about invasive diagnosis after first trimester assessment of risk for trisomy 21. Am J Obstet Gynecol 2005;193:322-26.

22. Egan JF, Benn P, Borgida AF, Rodis JF, Campbell WA, Vintzileos AM. Efficacy of screening for fetal Down syndrome in the United States from 1974 to 1997. Obstet Gynecol 2000;96979-85.
23. Platt LD, Green N, Johnson A, Zachary J, Thom E, Krantz D, et al. Sequential Pathways of Testing After First-Trimester Screening for Trisomy 21. Obstet Gynecol 2004;104:661-66.

24. Sharma G, Gold HT, Chervenak FA, McCullough LB, Alt AK, Chasen ST. Patients' preferences regarding first trimester aneuploidy risk assessment. Am J Obstet Gynecol 2005;193:1429-36.

25. Kornman LH, Wortelboer MJM, Beekhuis JR et al. Women's opinions and the implications of first- versus second-trimester screening for fetal Down's syndrome. Prenat Diag 1997;17:1011-18.

26. Mulvey S, Wallace EM. Women's knowledge of and attitudes to first and second trimester screening for Down's syndrome. Brit J Obstet Gynecol 2000;107:1302-05.

27. Zoppi MA, Ibba RM, Putzolu M, et al. Nuchal translucency and the acceptance of invasive prenatal chromosomal diagnosis in women aged 35 and older. Obstet Gynecol 2001;97:916-20.

28. Chasen ST, McCullough LB, Chervenak FA. Is nuchal translucency screening associated with different rates of invasive testing in an older obstetric population? Am J Obstet Gynecol 2004;190:769-74.

29. Chervenak FA, McCullough LB. The threat of the new managed practice of medicine to patients' autonomy. J Clin Ethics 1995;6:320-23.

30. Skupski DW, Chervenak FA, McCullough LB. Routine obstetric ultrasound. J Obstet Gynecol 1995;50:233-42.

31. Chervenak FA, McCullough LB, Chez R. Responding to the ethical challenges of managed care in the practice of obstetrics and gynecology. Am J Obstet Gynecol 1996;175:523-27.

32. Khushf G, Gifford R. Understanding, assessing and managing conflicts of interests. In McCullough LB, Jones JW, Brody BA (Eds): Surgical Ethics. New York: Oxford University Press 1988:342-66. 